\title{
Estimativa da erosão hídrica por meio do modelo USLE na sub-bacia Santa Rita em Pelotas-RS
}

O foco atual das pesquisas relacionadas ao meio ambiente tem sido na conservação dos recursos naturais, solo e água, visando a diminuição dos impactos antrópicos, de forma a tornar o uso dos mesmos sustentáveis. Nesse contexto, a bacia hidrográfica (BH) vem sendo utilizada como região geográfica nos estudos hidrológicos, sendo considerada como uma unidade ambiental, que possibilita tratar dos componentes e da dinâmica das inter-relações necessárias ao planejamento e a gestão ambiental. O objetivo deste trabalho foi estimar a perda de solo por erosão hídrica pela Equação Universal de Perda de Solo (USLE), para a sub bacia Santa Rita, inserida na Bacia Hidrográfica do Arroio Moreira Fragata e localizada em Pelotas (RS). Foram observadas perdas de solo menores que $10 \mathrm{Mg}$ ha-1, considerada como pequena ou nula, porém em algumas áreas chega a $50 \mathrm{Mg}$ ha-1, sendo classificada de moderada a média. A sub bacia Santa Rita pode ser considerada de baixa suscetibilidade a erosão hídrica.

Palavras-chave: Conservação; Bacia Hidrográfica; Práticas Conservacionistas.

\section{Estimation of erosion by Universal Soil Loss Equation in Santa Rita's basin}

\begin{abstract}
The current focus of research about the environment has been on soil and water and conservation of natural resources, aiming at reducing anthropic impacts, in order to make their use sustainable. In this context, the basin has been used as a geographic region in hydrological studies, being considered as an environmental unit, which makes it possible to deal with the components and dynamics of the interrelationships necessary for environmental planning and management. The aim of this research was to estimate soil loss by water erosion using the Universal Soil Loss Equation (USLE) for Santa Rita basin, localized in the Arroio Moreira Fragata Basin, in Pelotas, RS. In most of the basin, soil losses of less than $10 \mathrm{Mg}$ ha-1, considered as small, but in some areas it losses were $50 \mathrm{Mg}$ ha-1, being classified as moderate to medium. Santa Rita basin can be considered low susceptibility to water erosion.
\end{abstract}

Keywords: Conservation; Basin; Conservation Practices.

Topic: Engenharia de Recursos Hídricos

Reviewed anonymously in the process of blind peer.

Ivana Kruger Tuchtenhagen

Universidade Federal de Pelotas, Brasil

http://lattes.cnpq.br/8879548735698775

ivanatuchtenhagen@gmail.com

Marcelo Peske Hartwig

Escola Superior de Agricultura Luiz de Queiroz, Brasil http://lattes.cnpq.br/5440308443047200

marceloph@pelotas.ifsul.edu.br

Maria Cândida Moitinho Nunes

Universidade Federal do Rio Grande do Sul, Brasil

http://lattes.cnpq.br/3197317934141386

nunes.candida@gmail.com

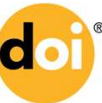

DOI: 10.6008/SPC2179-6858.2017.003.0009
Received: 24/02/2017

Approved: 23/04/2017

Referencing this:

TUCHTENHAGEN, I. K.; HARTWIG, M. P.; NUNES, M. C. M.; LIMA, C. L. R.; SILVA, T. P.; NACHTIGALL, S. D.. Estimativa da erosão hídrica por meio do modelo USLE na sub-bacia Santa Rita em Pelotas-RS. Revista Ibero-Americana de Ciências Ambientais, v.8, n.3, p.88-96, 2017. DOI: http://doi.org/10.6008/SPC2179-6858.2017.003.0009 


\section{INTRODUÇÃO}

A erosão do solo é considerada um dos maiores problemas ambientais, pois proporciona perdas de solo e de nutrientes, inundações, assoreamento e poluição de corpos hídricos (WANG et al., 2016). Segundo Panagos et al. (2015), o processo erosivo é afetado por diferentes fatores, como a cobertura do solo e as práticas de manejo.

O processo de degradação do solo tem se intensificado em áreas agrícolas, devido ao inadequado uso e manejo das terras, o qual acarreta impactos à agricultura e ao meio ambiente. Por isso, torna-se cada vez mais necessário o estudo das consequências da degradação e de inovadoras práticas que visem evitar e/ou minimizar esses problemas. Devido à importância do tema, existem modelos de predição de perda de solo, que são descrições matemáticas usadas para representar os processos erosivos em diferentes escalas (MOEHANSYAH et al., 2004; FERRO, 2010).

O modelo mais conhecido e utilizado na estimativa de erosão é a Equação Universal de Perda de Solo (USLE), desenvolvida no National Runoff and Soil Loss Data Center (Purdue University) em 1954 e sistematizada por Wischmeier et al. (1978), cujas variáveis são: a erosividade da chuva, a erodibilidade do solo, o comprimento de rampa e declividade do terreno, o uso e manejo do solo e as práticas conservacionistas empregadas.

A maior limitação ao uso de modelagem matemática para a predição de erosão dos solos consiste na dificuldade em trabalhar com uma grande quantidade de informações que descrevem a heterogeneidade da paisagem. Por esta razão, o uso Sistemas de Informação Geográficas (SIGs) aliado ao Sensoriamento Remoto, Sistemas de Posicionamento Global (GPS) e Cartografia Digital torna-se de extrema importância para a geração de informações que subsidiem estratégias de planejamento que visem o uso e o manejo racional do solo (CEMIN, 2013).

Considerando que este é um tema de suma importância para a conservação do solo e da água, e o fato desse ser o primeiro trabalho de predição de perdas de solo realizado para um futuro planejamento conservacionista na área de estudo, o objetivo deste trabalho foi quantificar as perdas de solo, por meio da Equação Universal de Perdas de Solo (USLE), para a sub-bacia Santa Rita, Pelotas/RS.

\section{MATERIAIS E MÉTODOS}

O estudo foi realizado na sub-bacia Santa Rita, localizada no município de Pelotas, no Rio Grande do Sul e inserida na Bacia Hidrográfica do Arroio Moreira (BHAM), conhecida como Bacia Hidrográfica Moreira/Fragata (Figura 1). A BHAM pertence à grande Bacia Litoral 40, do sistema hidrográfico do Rio Grande do Sul (L40-RS), situada no Sul do Estado. A sub-bacia Santa Rita apresenta uma área de 10,54 km² e está localizada nas coordenadas geográficas $64^{\circ} 95^{\prime} 5482,457^{\prime \prime}$ de Latitude Sul e $35^{\circ} 51^{\prime} 68,619^{\prime \prime}$ de Longitude Oeste. 


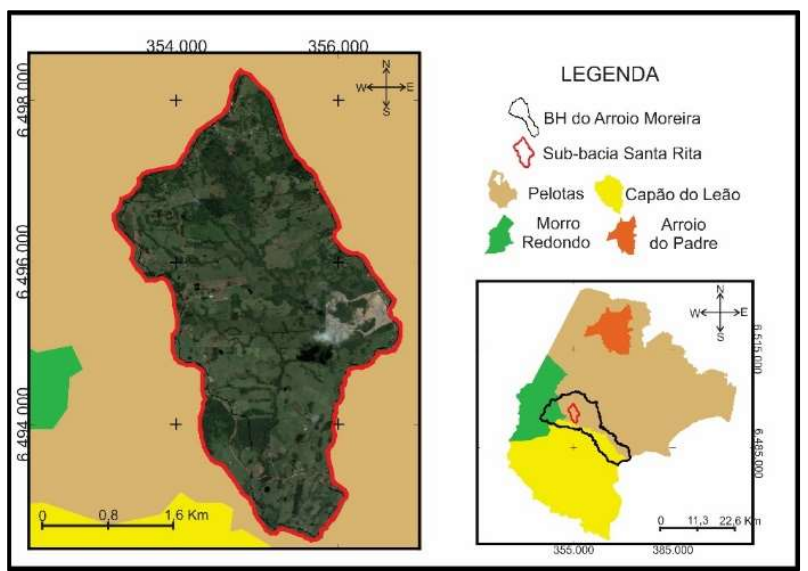

Figura 1: Delimitação da sub-bacia Santa Rita, localizada na Bacia Hidrográfica do Arroio Moreira-Fragata, Pelotas/RS.

De acordo com a classificação climática de Köppen, o clima da região é do tipo subtropical úmido (Cfa), com temperatura média de $12,5^{\circ} \mathrm{C}$ no mês mais frio e de $23,3^{\circ} \mathrm{C}$, no mais quente. A média anual de precipitação no município é de 1.385,6 mm (SANTOS, 2013). Os solos com maior representatividade na subbacia, de acordo com o mapeamento de Cunha e Silveira (1996), são: Argissolo Vermelho-Amarelo Distrófico (PVAd); Associação de Neossolo Regolítico, Neossolo Litólico e Argissolo Bruno-Acinzentado (RLd1); Argissolo Bruno-Acinzentado (PBACal) e Associação de Planossolo Háplico Eutrófico e Gleissolo Háplico (SXe3), conforme se nota na figura 2.

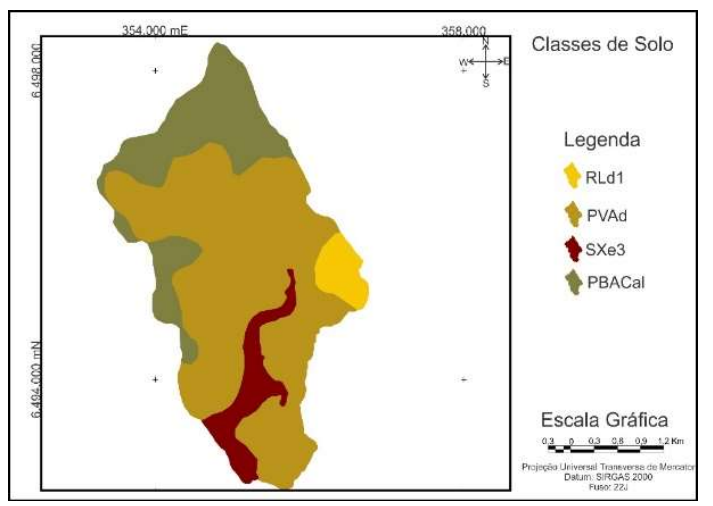

Figura 2: Solos predominantes na sub-bacia Santa Rita, localizada na Bacia Hidrográfica do Arroio Moreira/Fragata, Pelotas-RS.

A estimativa da perda de solo foi obtida pela Equação Universal de Perdas de Solo (USLE), descrita por Wischmeier et al. (1978), onde se tem que $A=R \times K \times L S \times C \times P$ (Equação 01), sendo que: $A$ = fator perda média anual de solo por unidade de área $\left(\mathrm{Mg} \mathrm{ha}^{-1} \mathrm{ano}^{-1}\right) ; \mathrm{R}=$ fator erosividade da chuva (MJ mm ha-1 $\mathrm{h}^{-1} \mathrm{ano}^{-1}$ ); $\mathrm{K}=$ fator erodibilidade do solo $\left(\mathrm{Mg} \mathrm{h} \mathrm{MJ}^{-1} \mathrm{~mm}^{-1}\right.$ ); $\mathrm{LS}=$ fator declividade e o comprimento de rampa (adimensional); $\mathrm{C}$ = fator uso e manejo do solo (adimensional); e $\mathrm{P}=$ fator práticas conservacionistas (adimensional).

O fator $\mathrm{R}$ expressa o potencial da chuva em causar erosão em uma área sem proteção (erosividade) (BERTONI et al., 2014). Este fator foi obtido a partir dos valores encontrados por Santos (2013), o qual utilizou dados de precipitação da Estação Climatológica de Pelotas/RS,localizada nas coordenadas 3145' Latitude Sul e 5221' Longitude Oeste e altitude de $13 \mathrm{~m}$, em uma série de 17 anos de precipitação, correspondente ao período de 1982 a 1998. 
O Fator $\mathrm{K}$ depende das características intrínsecas de cada tipo de solo, o qual está relacionado às propriedades físicas e químicas, representando a sua suscetibilidade em ser erodido (BERTONI et al., 2014). Os valores adotados foram obtidos a partir de dados bibliográficos para unidades pedológicas similares as da área em estudo, levando-se em consideração os valores encontrados em Levien (1988), Brasil (1997), Mannigel (2002), Carvalho (2008) e Ruthes (2012). O Fator LS é constituído por duas variáveis, o comprimento de rampa (L) e a declividade (S). Tanto o comprimento de rampa quanto a declividade influem diretamente sobre a direção e velocidade do deflúvio e sobre as perdas por erosão.

Para a determinação do comprimento da rampa utilizou-se o software SPRING (CÂMARA, 1996), versão 5.3. (Sistema de Processamento de Informações Georeferenciadas). Primeiramente foi realizada a edição dos divisores de água logo, importaram-se as imagens dos cursos d'água para a categoria Rampa do Modelo Digital de Elevação (MDE). Com o comando mosaico, adicionaram-se, em um único plano de informação, os cursos d'água, atribuindo-se a eles a função de linha de quebra, e os divisores de água como linhas cotadas. Em seguida, utilizou-se a ferramenta mapa de distâncias e selecionaram-se as linhas dos divisores de água, descarregando-se na mesma categoria, em um plano de informação chamado Fator $L$, onde foi produzida uma imagem e uma grade com os valores de comprimento da rampa.

O Fator LS foi calculado computacionalmente a partir do Modelo Digital de Elevação (MDE), proveniente da missão Shuttle 2236 Radar Topography Mission (SRTM) e desenvolvido pela National Aeronautics and Space Administration (NASA). A estimativa do valor de LS obteve-se pela equação desenvolvida por Bertoni et al. (1990). O fator foi adquirido pelo modelo digital de elevação (MDE), calculando-se em cada pixel os valores de comprimento de rampa e declividade e atribuindo dados à categoria do fator.

$\mathrm{Na}$ equação 2, tem-se que: $\mathrm{LS}=0,00984 \times \mathrm{L}^{0,63} \times \mathrm{S}^{1,18}$, sendo que: $\mathrm{LS}=$ fator topográfico (adimensional); $L$ = comprimento de rampa (m); e $S=$ declividade do terreno (\%). $A$ interpretação dos dados referente ao fator uso e manejo do solo (Fator C), foi realizada com conferencia em campo. Os valores adotados foram obtidos a partir de dados bibliográficos, que contemplam coberturas semelhantes às encontradas na área de estudo, considerando os valores encontrados nas pesquisas de Silva (2004) e Silva et al. (2007), que o uso do solo da área em estudo é de mata e campo, predominantemente.

O fator práticas conservacionistas (Fator P) representa o efeito de práticas de conservação, expressando a relação entre a perda de solo com determinada prática conservacionista e a correspondente perda quando a cultura está implantada no sentido do declive (WISCHMEIER et al., 1978). Devido às características da região, considerou-se que não existe a adoção de práticas conservacionistas de controle à erosão e, assim de acordo com Lee (2004), atribuiu-se o valor 1, cabe salientar que foram realizadas conferências 'in loco' (solo, relevo, cobertura, uso e manejo do solo e as práticas conservacionistas), para atribuição deste valor. Identificados e calculados todos os fatores que afetam o processo de erosão hídrica, foi possível estimar a perda de solo pela USLE, identificando as áreas mais suscetíveis à erosão na sub-bacia Santa Rita, conforme metodologia de Carvalho (2008). 


\section{RESULTADOS E DISCUSSÃO}

O valor médio anual da erosividade da chuva na sub-bacia é de $5.992,3 \mathrm{MJ} \mathrm{mm} \mathrm{ha}^{-1} \mathrm{~h}^{-1} \mathrm{ano}^{-1}$, conforme obtido no trabalho de Santos (2013) para a região de Pelotas. O mesmo estudo realizado para o município, foi encontrado o valor de 4918,9 MJ mm ha-1 $\mathrm{h}^{-1} \mathrm{ano}^{-1}$, conforme Lago (2000). Podendo classificar estas como erosividade moderada a forte, de acordo com Carvalho (2008). O Fator K obteve variação de 0,018 a $0,0533 \mathrm{Mg} \mathrm{h} \mathrm{MJ}^{-1} \mathrm{~mm}^{-1}$, como se pode notar na tabela 1. Os solos menos suscetíveis à erosão, com $\mathrm{K}$ entre 0,018 e 0,0320 $\mathrm{Mg} \mathrm{h} \mathrm{MJ}^{-1} \mathrm{~mm}^{-1}$, aparecem em maiores proporções, abrangendo $75,4 \%$ da área, demonstrando que, em âmbito geral, pode-se considerar uma bacia com solos de erodibilidade média (MANNIGEL et al., 2002). Toda via, a sub-bacia possui $24,6 \%$ de solos com alta erodibilidade, apresentando um valor de $0,0533 \mathrm{Mg} \mathrm{h} \mathrm{MJ}^{-1} \mathrm{~mm}^{-1}$.

Tabela 1: Erodibilidade dos solos da sub-bacia Santa Rita, localizada na Bacia Hidrográfica do Arroio Moreira-Fragata, Pelotas/RS.

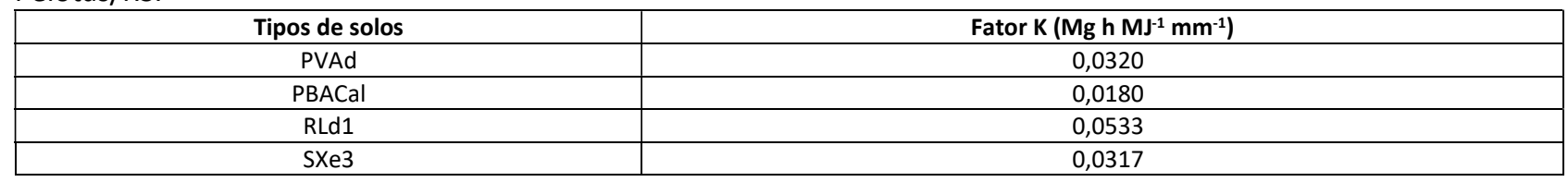

Fonte: Levien (1988); BRASIL (1997); Mannigel (2002) e Ruthes (2012).

Os solos analisados e propostos na tabela foram: Argissolo Vermelho-Amarelo Distrófico (PVAd); Associação de Neossolo Regolítico, Neossolo Litólico e Argissolo Bruno-Acinzentado (RLd1); Argissolo BrunoAcinzentado (PBACal) e Associação de Planossolo Háplico eutrófico e Gleissolo Háplico (SXe3). A sub-bacia Santa Rita apresenta pouca suscetibilidade a erosão.

De forma localizada, destacam-se algumas áreas de maior suscetibilidade, decorrentes de fatores topográficos localizados, como o maior declive do relevo. Dentre os solos presentes na bacia, o solo com menor erodibilidade é o Argissolo Bruno-Acinzentado (PBACal), que apresenta um valor de $0,0180 \mathrm{Mg} \mathrm{h} \mathrm{MJ}^{-}$ ${ }^{1} \mathrm{~mm}^{-1}$, classificado como de baixa erodibilidade, conforme se nota na figura 3 .

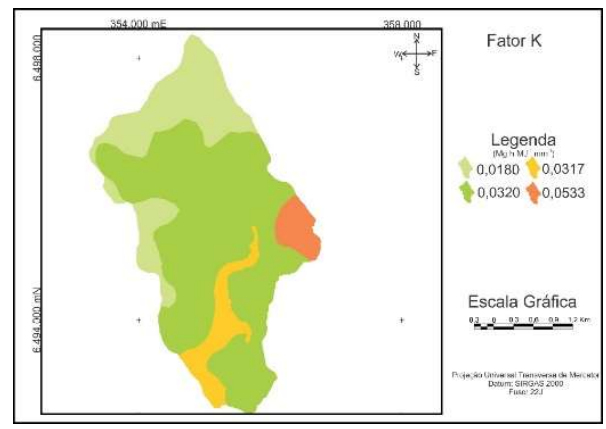

Figura 3: Distribuição de classes de solo da sub-bacia Santa Rita, localizada na Bacia Hidrográfica do Arroio MoreiraFragata, Pelotas/RS.

No Argissolo Vermelho-Amarelo Distrófico (PVAd) a erodibilidade foi maior do que no Argissolo Bruno-Acinzentado, apresentando um valor de $0,0320 \mathrm{Mg} \mathrm{h} \mathrm{MJ}^{-1} \mathrm{~mm}^{-1}$. Associação de Neossolos e Argissolo Bruno-Acinzentado (RLd1) foi a que apresentou maior erodibilidade $\left(0,0533 \mathrm{Mg} \mathrm{h} \mathrm{MJ}^{-1} \mathrm{~mm}^{-1}\right)$. Esse resultado pode estar relacionado ao fato de que os Neossolos encontrados na região são litólicos ou regolíticos, os 
quais são caracterizados por serem pouco profundos e com baixo teor de argila, e maior quantidade de areia, sendo esta mais suscetível a erosão hídrica.

O relevo predominante na área é ondulado (declividade de 8,1 a 20\%), ocupando 49,71\% da área em estudo, seguido do relevo suave-ondulado (declividade de 3,1 a 8\%), representando 39,44 \% da área, o plano (declividade 0 a 3\%) representa 6,24\% da área, e forte-ondulado (declividade de 20,1 a 45\%), representando 1,14\% da área total, conforme o atual Sistema Brasileiro de Classificação de Solos de 2014 (SANTOS et al., 2014), ilustrado na figura 4.

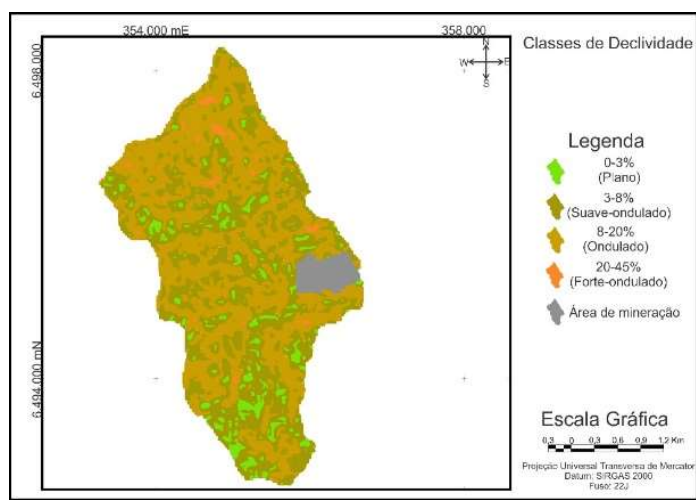

Figura 4: Classes de declividade da sub-bacia Santa Rita, localizada na Bacia Hidrográfica do Arroio Moreira/Fragata, Pelotas-RS.

O mapa de relevo apresenta os valores agrupados em classes para facilitar a interpretação. A variação do fator LS foi de 0 a 4, sendo que a menor classe $(0,0$ a 0,5) representa $45,61 \%$ da área, enquanto que a maior classe, LS de 3,5 a 4,0, apresentou $0,002 \%$ do fator LS, esboçado na figura 5 . Podendo considerar as áreas de declive acentuado insignificantes, devido a expansão da sub-bacia.

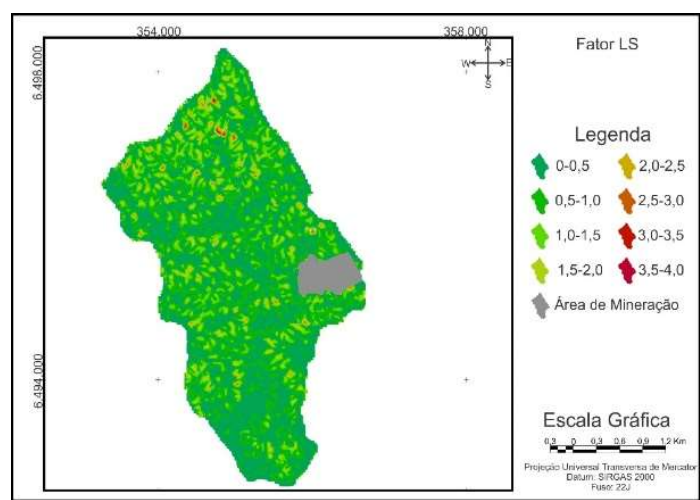

Figura 5: Classes do fator LS da sub-bacia Santa Rita, localizada na Bacia Hidrográfica do Arroio Moreira/Fragata, Pelotas-RS.

A partir das imagens obtidas e de conferências em campo, foi verificado o predomínio de campo nativo e áreas de pastagem cultivada, com atividade predominante de pecuária para gado de leite e de corte (58,79\%), seguido por mata (37,9\%). Cabe salientar, que a sub-bacia possui uma área de mineração, a qual representa 3,31 \% da área total, a qual não foi considerada para o cálculo da perda de solo. Sabe-se, entretanto, que esta atividade intensa de mineração representa uma das principais causas de degradação ao meio ambiente. 
Tabela 2: Cobertura dos solos da sub-bacia Santa Rita, localizada na Bacia Hidrográfica do Arroio Moreira-Fragata, Pelotas/RS.

\begin{tabular}{|c|c|}
\hline Cobertura do solo & Valor do fator C \\
\hline Mata & 0,001 \\
\hline Campo & 0,042 \\
\hline
\end{tabular}

Fonte: Silva et al. (2007); Silva (2004).

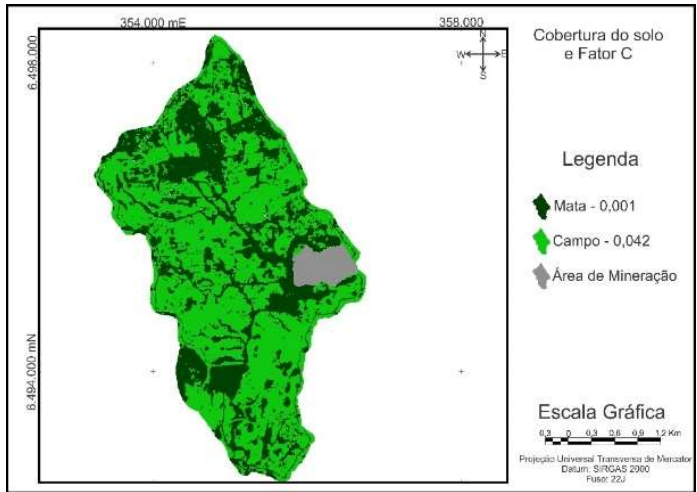

Figura 6: Mapa da cobertura do solo da sub-bacia Santa Rita, localizada na Bacia Hidrográfica do Arroio MoreiraFragata, Pelotas/RS.

De acordo com os valores obtidos e espacializados, observa-se que a maior parte da sub-bacia tem perda de solo inferiores a $10 \mathrm{Mg} / \mathrm{ha}^{-1}$, correspondendo a $87,85 \%$ da área total, sendo classificada como uma área de ocorrência de perdas de solo de nula a pequena, delineado na figura 7. Isso se deve, principalmente, ao fator topográfico, pois a área em estudo apresenta um relevo predominantemente ondulado, não apresentando áreas de declividade mais acentuado, o qual contribui diretamente para essa menor perda.

Outro fator que também influenciou no resultado encontrado é a cobertura do solo predominantemente de campo e mata, sendo áreas em que o manejo é praticamente inexistente, contribuindo para essa menor perda, principalmente quando associadas a solos que apresentam valores de erodibilidade baixa, como é o caso desta área. Pode-se observar também que, em algumas áreas, houve maiores perdas de solo, chegando a $50 \mathrm{Mg} / \mathrm{ha}^{-1}$. Da área total, 5,53\% apresentaram perdas de 10 a $15 \mathrm{Mg} / \mathrm{ha}^{-}$ ${ }^{1}$, classificadas como moderada e 3,16\% apresentaram índices de perdas de 15 a $50 \mathrm{Mg} \mathrm{ha}{ }^{-1}$, proposto na figura 7, considerado como valores médios de perdas de solo (CARVALHO, 2008), tais resultados demostram que as maiores perdas de solo ocorreram na parte superior da sub-bacia, ou seja, na região com o maior fator LS.

Os resultados encontrados para a perda de solo da sub-bacia se aproximam de Cemin et al. (2013), na Bacia Arroio Marrecas-RS, em que 78\% da área apresentam classes de perda de solo de nula a pequena. Segundo os autores, aproximadamente $10 \%$ da bacia apresentaram erosão moderada forte, sendo que estas áreas são representadas por solo descoberto, localizado, principalmente junto às estradas. Esses baixos valores se justificam pelas características da bacia, como a presença de poucas áreas com declividades acentuadas e pela pouca atividade antrópica, com predominância de matas e campo para pastagem na área. 


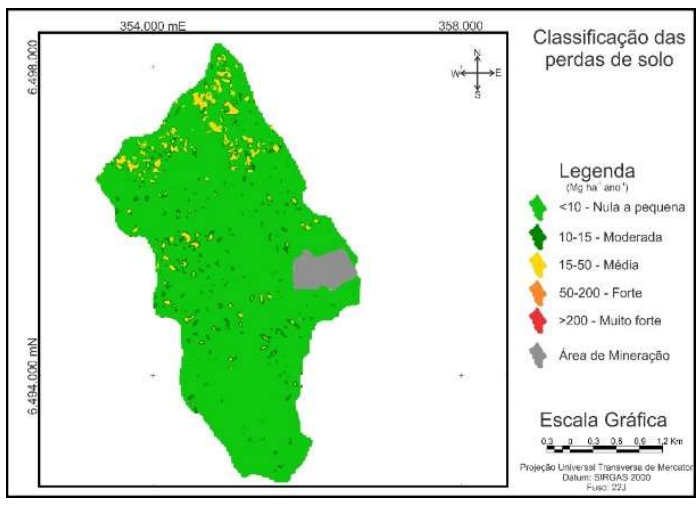

Figura 7: Estimativa de perdas de solo por erosão hídrica na sub-bacia Santa Rita, localizada na Bacia Hidrográfica do Arroio Moreira/Fragata, Pelotas-RS.

Com a implantação de práticas conservacionistas, diminui consideravelmente os processos erosivos, que se dão principalmente pelo arraste das partículas menores, ricas em nutrientes, culminando com decréscimo da fertilidade e, consequentemente, redução na produtividade $\mathrm{O}$ impacto da gota da chuva no solo reduz a capacidade de infiltração da água, devido a formação do selamento da superfície do solo, o qual ocorre a formação de escoamentos superficiais, resultando em uma maior perda de solo. Cabe salientar também, a importância de manter pastagens perenes na área, pois com a menor intensificação do manejo, ocorre menor perda, comparando com as culturas anuais.

Além de acarretar o arraste de sedimentos que possam conter insumos agrícolas, o qual provoca problemas de assoreamento e poluição dos cursos d'água, diminui a vazão dos leitos dos rios e aumenta os riscos de inundações, comprometendo a perenidade dos cursos. Deste modo, o estudo da erosão dos solos se torna importante, pois o conhecimento antecipado da suscetibilidade à erosão de um solo em área préestabelecida pode direcionar a atividade humana em relação ao uso e manejo sustentável dos recursos naturais.

\section{CONCLUSÕES}

O mapa representando a perda de solo permitiu verificar que os valores estimados para a perda de solo variaram de aproximadamente de $10 \mathrm{Mg} / \mathrm{ha}^{-1}$ a mais de $50 \mathrm{Mg} / \mathrm{ha}^{-1}$. A sub bacia Santa Rita pode ser considerada de pequena suscetibilidade, apesar dos fatores que favorecem a drenagem e a erosão. No entanto, de forma localizada, destacam-se algumas áreas de maior suscetibilidade, decorrentes do maior declive e erosividade. Conclui-se que a área em estudo, deve-se manter o predomínio de uso com pastagens perenes e mata, pois a adoção de cultivos anuais poderá incorrer em aumento das perdas de solo na região.

\section{REFERÊNCIAS}

BERTONI, J.; LOMBARDI NETO, F.. Conservação do Solo. 9 ed. São Paulo. Ícone, 2014.

BRASIL. Ministério do Meio Ambiente. Plano de Conservação da Bacia do Alto Paraguai (Pantanal): Análise integrada e prognóstico da Bacia do Alto Paraguai. Brasília: Ministério do Meio Ambiente, 1997.

CÂMARA, G.; SOUZA, R. C. M.; FREITAS, U. M.; GARRIDO, J.. SPRING: Integrating remote sensingand GIS by object- oriented data modelling. Computers and Graphics. v.20, n.3, p.395-403, 1996. DOI: https://doi.org/10.1016/00978493(96)00008-8

CARVALHO, N. O.. Hidrossedimentologia prática. 2 ed. Rio de Janeiro: 2008

CEMIN, G.; PÉRICO, E.; SCHNEIDER, V. E.; FINOTTI, A. R.. Determinação da perda de solos por erosão laminar na bacia 
hidrográfica do arroio Marrecas, RS, Brasil. Scientia Plena, v.9, n.1, p.1-9, 2013.

CUNHA, N. G.; SILVEIRA, R. J. C.. Estudo dos solos do município de Capão do Leão. Pelotas: UFPel, 1996.

FERRO, V.. Deducing the USLE mathematical structure by dimensional analysis and self-similarity theory. Biosystems Engineering, Silsoe, v.106, n.2, p.216-220, 2010. DOI: https://10.1016/j.biosystemseng.2010.03.006

\section{LAGO, J. C.. Erosividade das chuvas na metade sul do Rio} Grande do Sul. Tese (Doutorado) - Universidade Federal de Pelotas, Pelotas, 2000.

LEE, S.. Soil erosion assessment and its verification using the Universal Soil Loss Equation and Geographic Information System: a case study at Boun, Korea. Environmental Geology, v.45 n.4, p.457-465, 2004.

LEVIEN, R.. Erosão na cultura do milho em diferentes sistemas de cultivo anterior e métodos de preparo do solo. Dissertação (Mestrado em Agronomia) - Universidade Federal do Rio Grande do Sul, Porto Alegre, 1988.

MANNIGEL, A. R.; CARVALHO, M. P.; MORETI, D.; MEDEIROS, L. R.. Fator erodibilidade e tolerância de perda de solos do estado de São Paulo. Acta Scientiarum, Maringá, v.24, n.5, p.1335-1340, 2002. DOI:

https://dx.doi.org/10.4025/actasciagron.v24i0.2374

MOEHANSYAH, H.; MAHESHWARI, B. L.; ARMSTRONG, J.. Field evaluation of selected soil erosion models for catchment management in Indonesia. Biosystems Engineering, v.88, n.4, p.491-506, 2004. DOI: https://dx.doi.org/10.1016/j.biosystemseng.2004.04.013
PANAGOS, P.; BORELLI, P.; MEUSBURGER, K.; ALEWELL, C.; LUGATO, E.; MONTANARELLA, L.. Estimating the soil erosion cover-management factor at the European scale. Land Use Policy, v.48, p.38-50, 2015. DOI:

https://dx.doi.org/10.1016/j.landusepol.2015.05.021

RUTHES, J. M.; TOMAZONI, J. C.; GUIMARÃES, E.; GOMES, T. C.. Propriedades do Solo da Bacia Hidrográfica do Rio Catorze que intensificam a erosão laminar. Revista Brasileira de Geografia Física, v.1, n.1, p.160-169, 2012.

SANTOS, H. G.; JACOMINE, P. K. T.; ANJOS, L. H. C.; OLIVEIRA, V. A.; LUMBRERAS, J. F.; COELHO, M. R.; ALMEIDA, J. A.; CUNHA, T. J. F.; OLIVEIRA, J. B.. Sistema brasileiro de classificação de solos. 4 ed. Brasília: 2014.

SANTOS, J. P. Erosividade determinada por desagregação de chuva diária no lado brasileiro da Bacia da Lagoa Mirim. Dissertação (Mestrado em Manejo e Conservação do Solo e da Água) - Universidade Federal de Pelotas, Pelotas, 2013.

SILVA, A. M.; SCHULZ, H. E.; CAMARGO, P. B.. Erosão e hidrossedimentologia em bacias hidrográfica. 2 ed. São Carlos: Editora Rima, 2007.

SILVA, V. C.. Estimativa da erosão atual da bacia do Rio Paracatu (MG/GO/DF). Revista Pesquisa Agropecuária Tropical, v.3, n.34, p.147-159, 2004.

WANG, X.; ZHAO, X.; ZHANG, Z.; YI, L.; ZUO, L.; WEN, Q.; LIU, F.; XU, J.; HU, S.; LIU, B.. Assessment of soil erosion change and its relationships with land use/cover change in China from the end of the 1980s to 2010. Catena, v.137, p.256268, 2016. DOI: https://10.1016/i.catena.2015.10.004

WISCHMEIER, W. H.; SMITH, D. D.. Predicting rainfall erosion losses: a guide to conservation planning. Washington: USDA, 1978. 